\title{
A Rare Case of Bronchogenic Cyst Mistaken for Adrenal Tumor
}

\author{
Hae Do Jung ${ }^{1}$, III Young Seo ${ }^{2}$ \\ ${ }^{1}$ Department of Urology, Wonkwang University Sanbon Hospital, Gunpo, Korea \\ ${ }^{2}$ Department of Urology, Institute of Wonkwang Medical Science, Wonkwang University School of \\ Medicine \& Hospital, Iksan, Korea
}

Bronchogenic cysts are rare congenital malformations, most often occurring in the pulmonary parenchyma or posterior mediastinum. But they can develop in the ectopic area, especially in the retroperitoneal space. We report a case of adrenal bronchial cyst treated with laparoscopic excision. A 55-year-old woman was admitted with a left adrenal tumor on computed tomography during a study for dyspnea, cough, and sweats. The function of the adrenal glands was examined, and as a result, the adrenal tumors were determined to be nonfunctional. Magnetic resonance imaging showed about an 8-cm-sized large unilocular cystic lesion with mild and high signal intensities at left suprarenal fossa on T1 and T2 images. lodine-123 metaiodobenzylguanidine scan showed no scintigraphic evidence of neuroendocrine tumor in the left adrenal gland. We performed laparoscopic adrenalectomy with transperitoneal approach. The round, cystic mass was completely excised saving normal adrenal tissues. The operative time was 75 minutes and there was no definitive bleeding and complication. The pathologic tissue weighed $35 \mathrm{~g}$ and measured $88 \mathrm{~mm} \times 45 \mathrm{~mm} \times 28 \mathrm{~mm}$, and cystic changes were observed on the cut surface. The pathologic examination confirmed an adrenal bronchogenic cyst. We report a very rare disease, adrenal bronchial cyst, which could be easily and safely treated with laparoscopic surgery. (Korean J Urol Oncol 2019;17:186 -189)

Key Words: Bronchogenic cyst • Adrenal - Laparoscopy

Bronchogenic cysts are congenital malformations of the bronchial tree derived from the early embryonic foregut. Most frequently, they occur in the pulmonary parenchyma or in the posterior mediastinum. However, they can be developed in ectopic sites, especially in the retroperitoneal region. ${ }^{1}$ Treatment of all bronchial cysts is based on complete surgical resection and the diagnosis is confirmed by

Received October 4, 2019, Revised October 17, 2019,

Accepted October 17, 2019

Comesponding Author: Ill Young Seo

Department of Urology, Wonkwang University School of Medicine \& Hospital, 895 Muwang-ro, Iksan 54538, Korea

E-mail: seraph@wku.ac.kr

Tel: +82-63-859-1333, Fax: +82-63-858-1181

ORCID: https://orcid.org/0000-0003-2061-8214 the pathological results of the tissues obtained after resection. If the lesion is completely removed, the prognosis is usually good.

\section{CASE REPORT}

A 55-year-old woman was admitted with a left adrenal tumor on computed tomography (CT) during a study for dyspnea, cough, and sweats. The patient had been taking antihypertensive and cholesterol lowering medications for 7 years, and the blood pressure was well controlled. She also had 2 c-section surgeries. We investigated with adrenal function studies (plasma metanephrine, 24-hour urinary fractionated metanephrines, overnight 1-mg dexamethasone

This is an Open Access article distributed under the terms of the Creative Commons Attribution Non-Commercial License (http://creativecommons.org/licenses/by-nc/4.0/) which permits unrestricted non-commercial use, distribution, and reproduction in any medium, provided the original work is properly cited. 2019 (C) Copyright The Korean Urological Oncology Society and The Korean Prostate Society. All Rights Reserved. 
1-mg suppression test, the ratio of plasma aldosterone concentration to plasma renin activity) and concluded nonfunctional tumor. The results of adrenal function studies were nonspecific. Magnetic resonance image (MRI) showed about an 8-cm-sized large unilocular cystic lesion with mild and high signal intensities at left suprarenal fossa on T1(T1WI) and T2-weighted images (T2WI) (Fig. 1). I-123 MIBG scan showed no scintigraphic evidence of neuroendocrine tumor in the left adrenal gland.

We performed laparoscopic adrenalectomy with transperitoneal approach. There was a large amount of abdomi- nal fat. About 8-cm-sized round, cystic adrenal mass was observed (Fig. 2). Aspiration was done and a thick milkish fluid of $200 \mathrm{~mL}$ was drained. The mass was completely excised saving normal adrenal tissues. There was no increase in blood pressure during surgery. The operative time was 75 minutes and there was no definitive bleeding and complication. The pathologic tissue weighed $35 \mathrm{~g}$ and measured $88 \mathrm{~mm} \times 45 \mathrm{~mm} \times 28 \mathrm{~mm}$, and cystic changes were observed on the cut surface. Microscopically, the cystic wall was lined with pseudostratified columnar ciliated epithelium of respiratory type (Fig. 3). Cyst aspiration fluid showed a
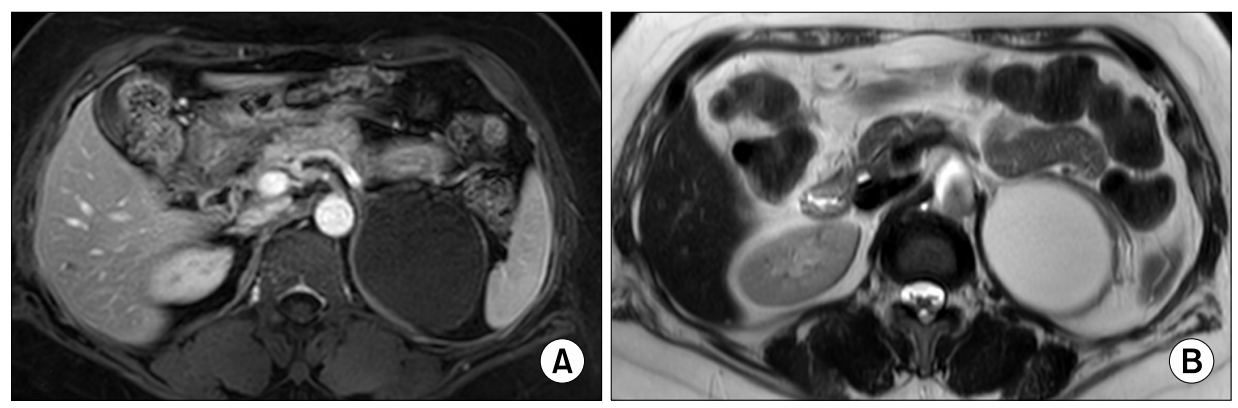

Fig. 1. About 8-cm-sized large unilocular cystic lesion with mild hyperintense signal on $\mathrm{T} 1$ image (A) and hyperintense signal on $\mathrm{T} 2$ image (B) at left suprarenal fossa on magnetic resonance imaging.
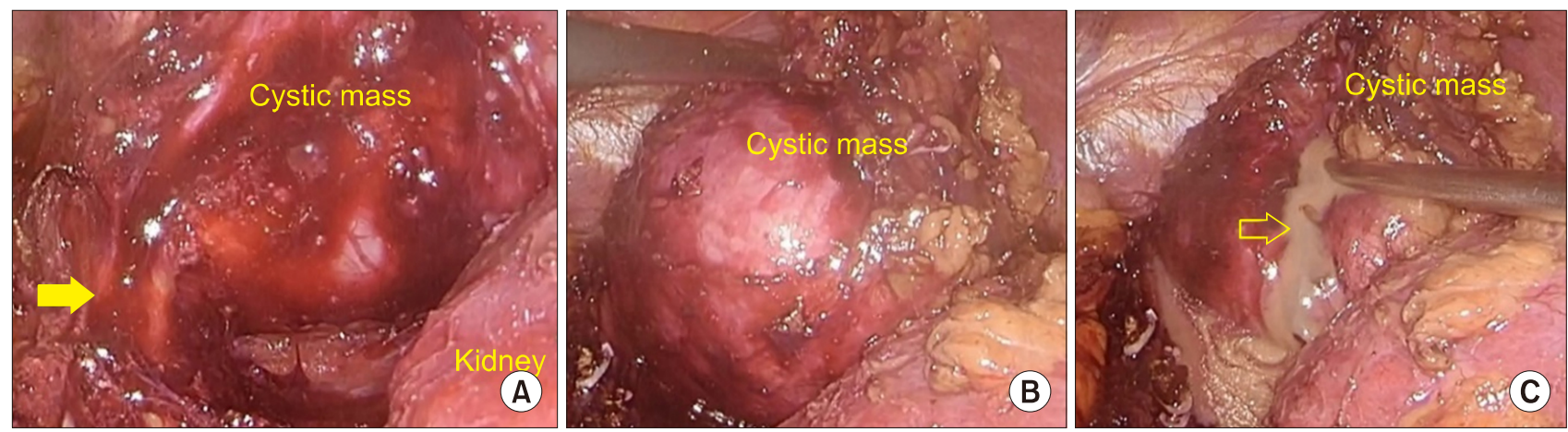

Fig. 2. (A) Dissected cystic mass abutting from normal adrenal tissue (arrow). (B) Huge cystic mass on the kidney. (C) Dark milky fluid (arrow) aspiration from the mass.
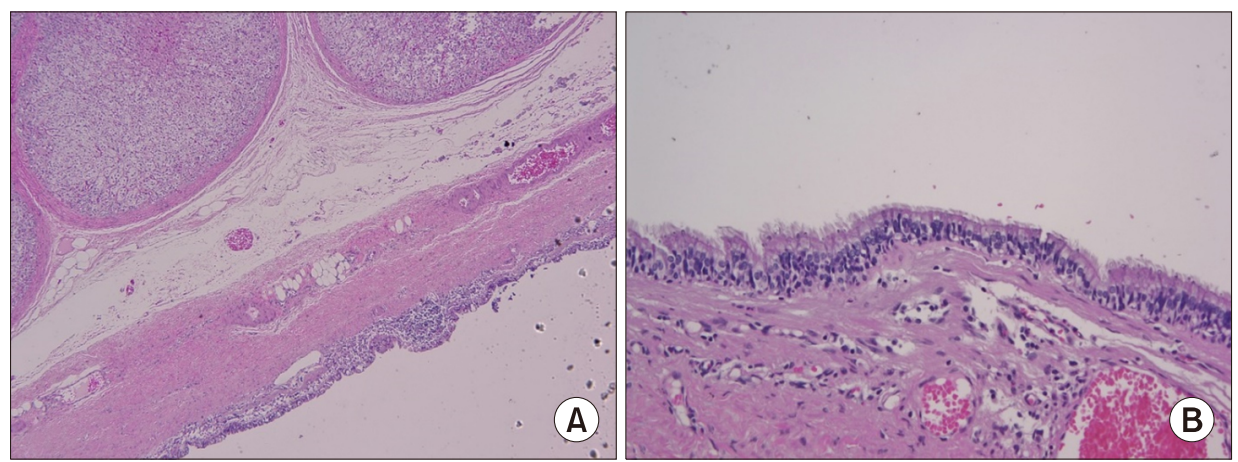

Fig. 3. Microscopic findings of the adrenal bronchogenic cyst. (A) Cystic lesion adjacent to the adrenal gland lined by respiratory-type epithelium, underlying lamina propria containing smooth muscle bundles $(H \& E, \times 100)$. (B) The lined epithelium composed of ciliated pseudostratified columnar epithelium $(H \& E, \times 200)$. 
few foamy histiocytes and inflammatory cells. The pathologic examination confirmed an adrenal bronchogenic cyst. There was no recurrence of tumor in abdominal CT at 3 months postoperatively and no abnormal findings in chest CT.

This study was approved by the Institutional Review Board of Wonkwang University School of Medicine \& Hospital (WUHIRB No. 2019-07-011).

\section{DISCUSSION}

Bronchogenic cysts are congenital foregut malformations that arise from an abnormal budding of the tracheobronchial tree during the 3 rd to 7 th week of development. ${ }^{2}$ They are typically found in the thoracic cavity or embedded in the pulmonary parenchyma. ${ }^{3}$ Bronchogenic cysts in the retroperitoneal region were first reported by Miller et al. in 1953 (quoted from ${ }^{1}$ ) and are extremely rare. ${ }^{4}$ Firstly Sumiyoshi et al. (quoted from $^{5}$ ) hypothesized that a retroperitoneal bronchial cyst can be resulted from pinching off and trapping of the abnormal buds of the tracheobronchial tree after migration in to the abdomen before fusion of the diaphragm components. $^{5}$

Retroperitoneal bronchogenic cysts can occur in a wide age range and are found equally in males and females. ${ }^{6}$ Among all cases of retroperitoneal bronchogenic cysts reported in the literature, $82 \%$ of cases occur in the left side of the retroperitoneal region. ${ }^{2}$ Current guideline suggests that investigations for adrenal incidentaloma should include hormonal workup and radiologic imaging. Hormonal workup includes plasma aldosterone concentration, plasma renin activity, plasma-free metanephrines and normetanephrines, and overnight dexamethasone suppression test. ${ }^{7}$ Generally, bronchogenic cysts appear as a well circumscribed cystic lesion accompanied with or without calcification and no significant contrast uptake on CT scan. ${ }^{8}$ On MRIs, those cysts were found to have low signal on T1WI but high signal on $\mathrm{T}^{\mathrm{WI}}{ }^{8}$

The differential diagnosis of a retroperitoneal cystic mass includes lymphangioma, mucinous cystadenoma, cystic teratoma, cystic mesothelioma, cystic metastasis, cysts of urogenital and foregut origin, such as Mullerian cysts or bronchogenic cysts, pancreatic pseudocysts, lymphoceles, urinoma, and hematoma. ${ }^{2}$ Histopathologically confirmed bron- chogenic cysts are usually unilocular and have thin walls lined by ciliated respiratory epithelium with bronchial glands, nerves, and cartilage. ${ }^{2}$

The resection must be complete because of the risk of recurrence after incomplete surgical removal. ${ }^{9}$ The treatment of asymptomatic bronchogenic cysts remains controversial. Most authors seem to advocate a surgical approach to prevent complications. The natural course of the cyst in retroperitoneal region is unknown, but the postoperative prognosis is mostly good. ${ }^{5}$

Currently preferred treatment is the removal of lesions, most often with minimally invasive surgery. Firstly, Tokuda et al. (quoted from ${ }^{10}$ ) successfully treated a retroperitoneal bronchogenic cyst with laparoscopy. In particular, large tumors larger than $6 \mathrm{~cm}$ have been removed with laparoscopic surgery. The choice of laparoscopy and retroperitoneoscopy is based on the operator's preferences, both with good results. $^{10}$

Adrenal bronchogenic cysts are very rare. They should be considered as differential diagnosis of nonfunctioning adrenal masses. Bronchogenic cysts can be diagnosed only by histologic confirmation. We report an adrenal bronchogenic cyst, which is easily and safely treated by laparoscopy.

\section{CONFLICT OF INTEREST}

The authors claim no conflicts of interest.

\section{REFERENCES}

1. Reichelt O, Grieser T, Wunderlich H, Möller A, Schubert J. Bronchogenic cyst. A rare differential diagnosis of retroperitoneal tumors. Urol Int 2000;64:216-9.

2. Yoon YR, Choi J, Lee SM, Kim YJ, Cho HD, Lee JW, et al. Retroperitoneal bronchogenic cyst presenting paraadrenal tumor incidentally detected by (18)F-FDG PET/CT. Nucl Med Mol Imaging 2015;49:69-72.

3. McAdams HP, Kirejczyk WM, Rosado-de-Christenson ML, Matsumoto S. Bronchogenic cyst: imaging features with clinical and histopathologic correlation. Radiology 2000;217:441-6.

4. Wang M, He X, Qiu X, Tian C, Li J, Lv M. Retroperitoneal bronchogenic cyst resembling an adrenal tumor with high levels of serum carbohydrate antigen 19-9: a case report. Medicine (Baltimore) 2017;96:e7678.

5. Mirsadeghi A, Farrokhi F, Fazli-Shahri A, Gholipour B. 
Retroperitoneal bronchogenic cyst: a case report. Med J Islam Repub Iran 2014;28:56.

6. Choi KK, Sung JY, Kim JS, Kim MJ, Park H, Choi DW, et al. Intra-abdominal bronchogenic cyst: report of five cases. Korean J Hepatobiliary Pancreat Surg 2012;16:75-9.

7. Başoğlu M, Karabulut K, Özbalcı GS, Aykun N, Çamlıdağ İ, Güngör BB, et al. Laparoscopic resection of retroperitoneal bronchogenic cyst clinically presenting as adrenal cyst. Turk J Surg 2018 Sep 11:1-3 [Epub]. https://doi.org/10.5152/turkjsurg.2018.4033.

8. Chen HY, Fu LY, Wang ZJ. Ileal bronchogenic cyst: a case report and review of literature. World J Clin Cases 2018;6:807-10.

9. Gharagozloo F, Dausmann MJ, McReynolds SD, Sanderson DR, Helmers RA. Recurrent bronchogenic pseudocyst 24 years after incomplete excision. Report of a case. Chest 1995;108:880-3.

10. Jannasch O, Büschel P, Wodner C, Seidensticker M, Kuhn $\mathrm{R}$, Lippert H, et al. Retroperitoneoscopic and laparoscopic removal of periadrenally located bronchogenic cysts--a systematic review. Pol Przegl Chir 2013;85:706-13. 